\title{
A Study on the Playing Style of Chinese Piano Works in the New Era
}

\author{
Huan Bi \\ College of Art, Yangtze University, Jingzhou, 434000, China
}

\begin{abstract}
As one of the important playing instruments at home and abroad, the piano has formed a certain scale in China after hundreds of years of development. Due to the great difference between Chinese music culture and western music, Chinese piano performance art contains a unique performance style and forms a distinct feature. On the basis of analyzing the cultural connotation and performance style of Chinese piano works, this paper expounds the specific performance style of Chinese piano works, and explores the performance style characteristics of Chinese piano works with specific cases for references.
\end{abstract}

Keywords: new era; Chinese piano works; performance style

\section{Introduction}

Piano is a western musical instrument. As a form of artistic performance, its playing style is an important means to better interpret the connotation of musical works. Influenced by western culture, Chinese piano works pay more attention to the integration of diverse cultures, and in the process of continuous innovation and development has formed a unique form of expression with Chinese characteristics, which better reflects the beauty of sound and artistic conception of Chinese national culture.

\section{The Cultural Connotation and Performance Style of Chinese Piano Works}

As one of the western musical instruments, the piano has been gradually improved with the development of western music, and has been recognized by piano lovers all over the world. Different times, different schools of art and different countries show great differences in artistic characteristics, forming different creation and performance styles in the continuous evolution. By playing different types of works, piano players embody their emotions and thoughts in performance, enriching the connotation of piano works and highlighting the charm of piano works.

The piano came to China in the early 20th century. Chinese performers continue to learn western performance skills and combine Chinese traditional culture to create many performance forms with Chinese national characteristics, adding a new vitality to the piano art. Chinese contemporary piano works integrate traditional cultural connotations with contemporary art forms. They not only have unique fingering in playing skills, but also make some innovations in traditional playing methods. By adapting the timbre and playing form of traditional piano works, the timbre features of Chinese national musical instruments are better highlighted, and the combination of virtuality and reality, rigor and softness is achieved in the performance, which better shows the changes of Chinese piano playing form and profound

Copyright $(2019$ by author(s) and Frontier Scientific Research Publishing Inc.

This work is licensed under the Creative Commons Attribution International License (CC BY 4.0).

http://creativecommons.org/licenses/by/4.0/ 
cultural background.

\section{The Performance Style of Chinese Piano Works}

In the development of piano performance art in different countries, the most important thing is the display of national style in the performance process. Through continuous practice and innovation, Chinese pianists have summed up a lot of performance experience. Through the fusion of traditional culture and modern art, they have better demonstrated the cultural connotation of the works and formed a unique performance style with Chinese characteristics.

\subsection{Phonological expression}

Under the influence of Chinese traditional culture, the performance of Chinese piano works pays more attention to the expression of lasting appeal and regards the melody of piano works as the soul of piano music. Therefore, under the background of the new era, Chinese pianists pay more attention to the unity of the middle form and the god, and pursue the beauty of the whole melody. On the basis of emphasizing the vivid and flexible phonology, the artistic conception of the music is better highlighted, and the ups and downs of the melody are used to enrich the sense of fluidity and line of the piano music, so that the piano playing has more lasting appeal. For example, the modern works "liuyang river" "colorful clouds chasing the moon" are unified in the process of playing. Through the polishing and adjustment of the details of the works, we can examine the works from an overall perspective, and better reflect the characteristics of Chinese modern music in terms of the treatment of rhyme, thus forming a natural and smooth playing style.

\subsection{The expression of timbre}

Timbre is an important part of the verve in the performance of piano works, it is the deep embellishment of piano tunes, and it is an important embodiment of the delicacy of Chinese piano performance. In the development of Chinese traditional piano performance, enough attention has been paid to the expression of timbre. Pianists believe that piano performance pays more attention to the individuality of playing and the uniqueness of timbre. Therefore, the performance characteristics pursued by Chinese pianists are not the standardization of timbre, but the diversification of timbre, so as to better highlight the characteristics of piano instruments and express the uniqueness of Chinese national music. In combination with the timbre characteristics of Chinese national instruments, the intensity and volume of piano playing are adjusted to simulate the playing sounds of different instruments, so as to match the rhythm of traditional instruments and promote the integration of traditional Chinese music and piano. For example, when playing Chinese zither works on the piano, the player needs to bend the fingers, keep the finger strength inward and concentrate all the power on the fingertips, so as to ensure the flexibility of playing with the zither and better complete the interpretation of Chinese folk music works.

\subsection{Change of rhythm}

Chinese art has a special pursuit for the beauty of lines. It not only attaches importance to the beauty of lines created in calligraphy, painting, architecture and other fields, but also attaches importance to the sense of rhythm of music performance. Under the multicultural background, Chinese piano performance pays more attention to the freedom of rhythm and better interprets the rich and varied emotions in the rhythm change, giving people a refreshing feeling. The change of playing rhythm in contemporary piano works enriches the expressive tension of piano works and adds more color and vitality to modern piano performance. For example, piano song "song of the phoenix" is characterized by its varied rhythm, which reflects the unique aesthetic taste of Chinese piano art and has become a classic work of piano performance in the new era.

\subsection{The expression of musical conception}

Chinese music playing art attaches great importance to the expression of the artistic conception of the works, and stresses on placing the spiritual connotation of the music in the performer's emotion during the playing process, thus 
providing more broad imagination space for the audience and being infected by the piano music. Liu Guosong, a famous artist, believes that the beauty of Chinese art lies not in the external, but in the combination of the external and internal beauty of the works, which gives people the space for guidance and imagination, namely the space for artistic creation and expression, thus enhancing the depth and breadth of artistic expression and presenting the artistic effect of moistening things silently. In terms of piano playing, this concept should also be integrated and utilized to internalize the beauty of artistic blank in performance, thus arousing the inner resonance of the audience. Taking the piano works "the setting sun drum" as an example, the player uses the change of rhythm and the fluency of playing on the basis of expressing his own emotion to constantly increase the performance of the works and bring people a new audio-visual experience.

\section{Interpretation of the Playing Style of Chinese Piano Works}

\subsection{Xu Zhenmin's playing style}

As one of the pianists in the new era of China, Xu Zhenmin's playing style is characterized by the fusion of Chinese traditional music and piano music, creating a new playing style and pointing out the development direction for Chinese piano playing art. His major piano works include "jiangsu folk song", the concerto "crossing the river symphonic poem", the fantasy overture "snow plum garden", and the poem "maple bridge". The performance style is very individual, which is mainly reflected in the variety of timbre, and it is good at using the expression techniques of harmony and transfer to highlight the transformation of piano syllables, which not only has the characteristics of traditional music art, but also can reflect the innovative aesthetics of modern piano art, with strong artistic appeal. Taking "deng youzhou taige" as an example, this paper makes a specific analysis of Xu Zhenmin's playing style. "deng youzhou taige" is a piano piece that breaks through the limitation of music rhythm, uses the 12-tone system to highlight the magnificent momentum of music, and adds the traditional national pentatonic mode on the basis of music structure. The whole structure can be divided into three parts: the beginning part, the middle part and the repeated part. At the beginning, the melody and rhythm presented in the part are full of changes, and there are frequent syllable conversion. It seems that the tone played is irregular, but it is coordinated and unified with the following repeated parts, so that the overall playing style has distinct characteristics. The performance style of this piano works can not only reflect the harmony and fluency of modern playing mode, but also highlight the magnificent momentum of the program. Meanwhile, it uses modern music creation techniques to show the artistic conception of traditional culture, which is impressive and memorable.

\subsection{Ding Shande's playing style}

As the most influential pianist in the field of Chinese music in the 20th century, Ding Shande created many piano pieces with Chinese national characteristics, formed a distinctive piano playing style, and pioneered the theme of national music in Chinese piano. His main piano playing works are "tokata good news", "xinjiang dance music", "happy festival". Piano performance style is mainly melodic, using variation to show the overall structure of the piano program and complete the emotional expression of the piano program. Taking "xinjiang dance no. 1" as an example, Ding Shande used three-step form to show the richness of the contents of the repertoire. At the beginning of the performance, the six notes in a group of beats are repeated, with multi-level variations and repeated playing techniques to show the joy and enthusiasm of the music. In the middle stage, lyrical performance technique is used to form a sharp contrast with the beginning stage, to change the tone of the whole music and show the unique tragic emotion in the repertoire. In the middle stage of the piano playing, the crying tone is used to decorate the whole section, while the playing of continuous parallel small second harmonies intensifies the expression of grief in the music. In the final stage of the performance, the whole music goes back to the beginning stage, and the tone of the third degree is improved to increase the cheerful atmosphere, which better shows the situation of Xinjiang people's love for dancing and pushes the music playing to the climax. 


\subsection{Wang Jianzhong's playing style}

Wang Jianzhong is a piano player and composer who has been dealing with piano all his life. His special growth experience became an important source of inspiration for his music creation and playing. His main works are "tokato", "tian ge", the adaptation of the music is "red flowers", "song of the phoenix", "turn over daoqing". Taking the adaption song "song of the phoenix" as an example, Wang Jianzhong deleted the structure of the circulation body of the original song, and changed the original song into eight selections, which were prelude, four melodies and three technical expressions. This kind of segmentation is different from that of traditional piano music. It uses the closeness of the cohesion of each paragraph to reduce the sense of fragmentation of the piano music, giving a sense of integration. During the performance, a variety of grace notes and harmony full of life atmosphere were placed, which more vividly simulated the scene of birds arguing, highlighted the vitality of playing, and better expressed their love for the ecological environment. Both the musical structure and playing skills of his piano repertoire are better than the original. The harmonies used are fresh and full of charm, and the expression techniques used are just right. In terms of playing, he has his own unique views, that is on the basis of maintaining national characteristics, he uses piano playing techniques to express Chinese flavor and artistic conception, which fully shows the charm and musical style of Chinese piano playing.

\section{Conclusions}

In a word, Chinese piano playing style has distinct national characteristics. It not only attaches importance to the application of timbre and timbre, but also attaches importance to the control of rhythm, so as to better reflect the artistic charm of Chinese music culture and adds new vitality to the development of piano playing art.

\section{Conflicts of Interest}

The author declares no conflicts of interest regarding the publication of this paper.

\section{References}

[1] Zhao B.T. (2019). The Importance of Piano Work Analysis in Piano Performance, Drama House, 30, 64.

[2] Chi X. (2019). On the Influence of the Evolution of Piano Style on Piano Technique, Voice of the Yellow River, 15,31 .

[3] Tan M.K. (2019). On the Style Characteristics of Chinese Piano Works and the Emotional Grasp of Performance, Drama House, 26, 70.

[4] Luo S.T. (2019). On the Coordination and Function of Sight, Hearing and Touch in Piano Performance Teaching, Northern Music, 39(11), 182+184. 